\title{
Key success factors of health research centers: A mixed method study
}

\author{
Shahram Tofighi ${ }^{1}$, Ehsan Teymourzadeh ${ }^{1}$, Majid Heydari ${ }^{2}$
}

${ }^{1}$ Ph.D. of Health Services Management, Assistant Professor, Health Management Research Centre, Baqiyatallah University of Medical Sciences, Tehran, Iran

${ }^{2}$ Ph.D. Candidate of Health Policy, Health Management Research Centre, Baqiyatallah University of Medical Sciences, Tehran, Iran

\section{Type of article: Original}

\begin{abstract}
Background: In order to achieve success in future goals and activities, health research centers are required to identify their key success factors.

Objective: This study aimed to extract and rank the factors affecting the success of research centers at one of the medical universities in Iran.

Methods: This study is a mixed method (qualitative-quantitative) study, which was conducted between May to October in 2016. The study setting was 22 health research centers. In qualitative phase, we extracted the factors affecting the success in research centers through purposeful interviews with 10 experts of centers, and classified them into themes and sub-themes. In the quantitative phase, we prepared a questionnaire and scored and ranked the factors recognized by 54 of the study samples by Friedman test.

Results: Nine themes and 42 sub-themes were identified. Themes included: strategic orientation, management, human capital, support, projects, infrastructure, communications and collaboration, paradigm and innovation and they were rated respectively as components of success in research centers. Among the 42 identified factors, 10 factors were ranked respectively as the key factors of success, and included: science and technology road map, strategic plan, evaluation indexes, committed human resources, scientific evaluation of members and centers, innovation in research and implementation, financial support, capable researchers, equipment infrastructure and teamwork.

Conclusion: According to the results, the strategic orientation was the most important component in the success of research centers. Therefore, managers and authorities of research centers should pay more attention to strategic areas in future planning, including the science and technology road map and strategic plan.
\end{abstract}

Keywords: Key factors, Success, Research Centers

\section{Introduction}

In today's world, science and technology, by their wide growth and development, are considered as important factors of the economic, social and cultural development process. Therefore, research and training institutions and systems have become more important. One of the main organizations of the research system in each community is the research center (1). Today, research centers are recognized as being one of the most important research and development organizations in society. These centers, along with universities have a major role in the production and dissemination of science and technology in a country. That's why success in this context is important (2). Success means realizing the benefits, and achieving these benefits requires the provision of needed factors (3). There are a limited number of key areas for any organization in which everything in those areas should be done correctly to achieve success and progress (4). Identifying these critical factors is one of the most important steps of planning for the future of the organization (5). Each organization requires providing factors necessarily to achieve their goals. In fact, for any organization, there are areas of activity that should be done in the best possible way to achieve the

\section{Corresponding author:}

Majid Heydari, Health Management Research Centre, Baqiyatallah University of Medical Sciences, Tehran, Iran. Tel: +98.2144056127, Fax: +98.2144055436, Email: majidheydari67@gmail.com

Received: October 22, 2016, Accepted: January 27, 2017, Published: August 2017

iThenticate screening: January 28, 2017, English editing: May 12, 2017, Quality control: Kuly 12, 2017

(C) 2017 The Authors. This is an open access article under the terms of the Creative Commons Attribution-NonCommercialNoDerivs License, which permits use and distribution in any medium, provided the original work is properly cited, the use is non-commercial and no modifications or adaptations are made. 
objectives that have been defined for itself. These factors, which are called critical success factors in management literature, are integral components of an organization's success in achieving their goals (6). In fact, these factors are the major bottlenecks of an organization in achieving the mission and vision. These factors can exist either as obvious or hidden. It is important to be able to identify them through scientific methods (7). To determine critical success factors is important, because it can be a support for implementation of organization strategic scenarios without wasting extra costs. These factors are associated with organizational goals and are necessary for realizing the objectives, and furthermore, are also appropriate for the organization's competitive strategies (8). Many studies have been done regarding the key success factors of organizations, but the research literature of this study shows that studies on the key factors of success in research centers are low and dispersed (9). In a similar study, key success factors in R \& D projects were studied for public research centers in Mexico. In this study, key elements were examined and categorized in 8 groups, and included: process $\mathrm{R} \& \mathrm{D}$, project planning, work and collaboration networks, human resources, market, financial resources, organization, and quality (10). In another study, key factors of success in science and technology parks in Sweden were studied, in which, links with university, closeness to suppliers and users, availability to researchers and experts, and relationships between the institutions in the park were recognized as the most important factors of success (11). In Iran, studies on success factors of science and technology parks have been done $(6,9,12)$, however, most of the previous studies do not take into account the success of academic research centers. Research centers, like any other institution or organization, require the provision of factors and conditions that ensure success to achieve their missions. Therefore, the main objective of this study is to explore and rank the key success factors of research centers at one of the medical universities in Iran.

\section{Material and Methods}

\subsection{Research design and setting}

This study is a mixed method quantitative-qualitative that was conducted between May and October in 2016. In order to determine the key success factors, first, through a qualitative study, we needed to extract all factors, and in the next phase, rank them using a quantitative method Therefore, a mixed method was used in this study. Research setting was 22 research centers in one of the medical universities in Iran. The study was conducted in qualitative and quantitative phases.

\subsection{Qualitative phase}

In this phase, the aim was to extract the factors affecting the success of research centers. In this phase, data collection was through semi-structured interviews. The following questions were used in interviews.

1) Which intra organizational factors play an important role in the success of your research centers?

2) Which extra organizational factors play an important role in the success of your research centers?

3) Which intra and extra organizational factors are barriers in the success of your research centers?

Interviews were conducted purposefully with members who had the most information in this regard. Ten interviews were conducted and with the saturation of data, sampling and data collection were ended. Interviews were held in the center's conference hall, and each took between 50 to 60 minutes. After each interview, the transcription was immediately analyzed by using content analysis and thematic analysis. (13). After transcription, for familiarization with the data, texts were read several times and then initial coding was done by two researchers. By reviewing, summarizing and classifying initial codes, related themes were identified. By revising and completing the identified themes, finally, the main themes and sub-themes were identified and classified. After discussing and resolving the different items by two researchers, the dependability of extracted codes and themes were ensured. Also, for credibility of data, results were referred to interviewees to confirm them.

\subsection{Quantitative phase}

After identifying the factors affecting the success of centers in the qualitative phase, a questionnaire has been prepared with extracted factors. The research team in collaboration with 3 experts of centers, designed the questionnaire. Then as the pilot, the questionnaire was distributed randomly among ten members of centers. Finally, validity of the questionnaire by experts' opinion and its reliability, was confirmed by Cronbach's alpha test $(\alpha=0.916)$. The questionnaire had nine main themes and 42 sub-themes. To assess the importance of each of the factors and components of the questionnaire, five-point Likert scale was used which had an ordinal scale. At this scale, 1 was the lowest and 5 was the highest importance. The study population consisted of all managers, directors, deputies, officials, experts and faculty members of the research centers. Study inclusion criteria included members with at least 5 years' experience and permanent members of centers. According to the inclusion criteria, in total, 68 people were eligible. Due to the low sample size, all these people were selected and the questionnaire was distributed by census method among 68 members. Questionnaires were delivered to heads of research centers, and a 
week later, researchers, by referring to centers, collected them. Incomplete questionnaires were followed up twice and then data collection ended. In total, 54 members were ready to complete it. The response rate of the questionnaire was $80 \%$. The collected data were entered into the SPSS20 software, and to rank and identify the importance of extracted factors, Friedman test was used.

\section{Results}

\subsection{The findings of the qualitative phase}

Nine main themes and forty-two sub-themes were identified. Main themes were named based on the nature of the sub themes, including "strategic orientation", "human capital", "support", "communication and cooperation", "infrastructure", "management", "paradigm /ideological", "innovation" and "projects".

\subsubsection{Theme 1: strategic orientation}

Findings showed that one of the main components of success in research centers is strategic orientation, which is composed of five factors:

1) Strategic plan

2) Science and technology roadmap

3) Research needs assessment

4) Evaluation indexes

5) Research policy (the state and university level)

Most participants believed that strategic plan, roadmap and stability in policies are the main factors of success. One participant in this regard said: "I think that having strategic plan, road map and intelligent goals design is very important." (Participant 4). Another said: "besides an appropriate strategic plan and road map, needs assessment, right evaluation and feasibility study are also a great help for success.” (Participant 8).

\subsubsection{Theme 2: Human Capital}

Human capital was identified as the second main component of the study, which is composed of the following five factors:

1) Capable researchers

2) Local students and elites

3) Foreign professors and students

4) Human resources proportion with the objectives

5) Committed human resources

All the participants in this theme believed that human capital was the key element of every research organization. They believed that use of interested researchers, famous specialists, researchers with high confidence and committed and local and foreign elites, make centers more effective. One participant said: "I would like to say that worthy and capable people are necessary for research activities. Also, centers, by use of internal and external professors and students together, can be successful in the exchange of new knowledge." (Participant 6).

\subsubsection{Theme 3: Support}

Another theme in this study, which was identified as affecting the success of research, was advocacy and support. The extracted sub-themes include the five following factors:

1) Political support

2) Financial and budget support

3) Officials' moral support

4) Grants

5) Grants distribution

Almost all participants acknowledged supporting factors both inside and outside of the centers as one of the main success factors. Three types of support including financial, political and moral support were mentioned by almost all participants. One participant said: "financial support from the university and the ministry of health, with the moral and political support of former administrators of our centers were key success elements in recent years." (Participant 10). Some of the participants believed that in addition to the centers' budget, grants and distributing them between researchers and centers are also important in success.

\subsubsection{Theme 4: Communication and Collaboration}

This theme is composed of four sub-themes:

1) Teamwork/group work (among members - among centers) 
2) Networking

3) International interactive and researches

4) National collaborative researches

All participants declared that communication within and between the centers was a very important factor in achieving the goals and mission. A participant said: "integration of concerns, networking and joint activities of centers have positive roles in the success." (Participant 2). Half of the participants mentioned that poor communication with other research centers in the country and abroad is a barrier for success achievement.

\subsubsection{Theme 5: Infrastructures}

Infrastructures were extracted as one of the main themes for success in research centers in this study. This theme is composed of the following four factors:

1) Conceptual infrastructure (rules, procedures, values)

2) Information infrastructure

3) Physical space infrastructure

4) Equipment infrastructure

Most of the participants paid particular attention to the role of physical and equipment infrastructures, especially centers with laboratory activities. Also, all the participants stated following the centers laws, regulations and organizational values and existence of explicit work processes are basic infrastructure. Automation system, unique equipment, facilities and integrated information systems were other items that were mentioned by participants.

\subsubsection{Theme 6: Management}

This theme is composed of six factors:

1) Management and development of research human capital

2) Compensation and rewarding system

3) Scientific evaluation of centers and individuals

4) Research ethics and intellectual property rights

5) Implementation of laws, regulations and guidelines

6) Administrative bureaucracy

The majority of participants mentioned that personal and organizational motivation facilitates the process of recruitment, scientific evaluation, ethical issues in research, effective rewarding system and complexity and length of the working process important in centers management. A participant said: "one of the serious issues in centers management is the elimination of administrative bureaucracy and developing an automation system." (Participant 8). Recruitment, retention and development of human capital were common points between all participants in this theme. Also, two participants stated faculty members' promotion should be based on new scientific evaluation methods.

\subsubsection{Theme 7: Paradigm/Ideological}

Another concept that was extracted, and is effective in success of research centers was paradigm or ideology. This theme is more related to attitudes about the research and researcher, and is composed of three factors:

1) Officials' systematic thinking

2) Ethics and spirituality

3) Value based approach to research and researcher

Type of manager's perspective to researches and researchers, and their systematic thinking in research field were mentioned by participants as key factors. They believed that just understanding the importance of research and systematic view at national level our goals can be reached.

\subsubsection{Theme 8: Innovation}

Innovation is another theme that is extracted in this study. This theme is composed of three factors:

1) Innovation in research and implementation

2) The commercialization of research products

3) Competitive climate (among members and centers)

Most participants remarked that having creativity and innovation in research is important. They stated that creating competition among members and centers leads to innovative researches. One participant said: "by following researchers of the western countries' medicine research is a threat to our centers." (Participant 5). Also, a participant believed "when research results of a center become a commercial product, that center can claim success." (Participant 1) 


\subsubsection{Theme 9: projects}

The final extracted theme discussion about projects and plans, this theme is composed of the following seven factors:

1) Quality of projects

2) The quantity of projects

3) Special research areas

4) Publication of results

5) Time for project approval

6) Sequential or serial researches

7) Diversity of new research titles

Nearly all the participants pointed to the quality of projects and addressing new areas for research. According to some of the participants, restrictions on the publication of some project results could be a barrier to the success of centers. Believing the sequential researches and avoiding fragmented researches was emphasized by participants. A participant declared that, time for project approval should be shorter, he said: "the long process of project approval is a barrier to the activities and achieving the goals of the centers." (Participant 9).

\subsection{The findings of the quantitative phase: Ranking factors}

In this phase, $90 \%$ of the participants were male and $10 \%$ were female. Thirty percent of participants were managers of centers, $20 \%$ deputies, $40 \%$ faculty members and $10 \%$ experts of centers. In Table 1, the results of statistical significance and ranking of the main themes on the success of research centers is shown. According to the findings in Table 1, results of Friedman significant tests show mean rank of nine main themes with $95 \%$ confidence interval not equal, and are significant at $\mathrm{p}=0.000$ levels. Also, among nine main themes, themes of "strategic orientation" with mean rank of 7.79, "management" with 7.71 and "human capital" with 6.44 are respectively the three main components of success in research centers. Themes of "support", "project and plan", "infrastructure", "communication and collaboration", "paradigm and ideological" and "innovation" are ranked next. Table 2 shows the results of statistical significance and ranking of the sub-themes in each main theme. According to the results in Table 2, with $95 \%$ confidence interval, mean rank of factors associated with the nine main components is not equal, and they are at significant level $(\mathrm{p}<0.05)$. Also in the strategic orientation component, factors of "science and technology roadmap", "strategic plan" and "evaluation indicators", in the management component; "scientific evaluation of individuals and centers" and " management and development of human capital", in human capital component; "capable and committed human resource", in the support component; "financial and budget support", in project component; "plan quality" and "result publishing", in the infrastructure component; "equipment infrastructure", in the communication and collaboration component; "teamwork between members and centers", in the paradigm component; "value based approach to research and researcher" and in the innovation component; "innovation in research and implementation" have the highest mean ranks. These factors identified as the most important factors in each component of success in research centers. In table 3, 10 key factors of the 42 identified success factors are listed in order of rank. According to the results, the first three key factors of success in research centers are: "science and technology road map" with mean rank of 29.84, "strategic plan" with mean rank of 29.61 and "evaluation indexes" with mean rank of 28.55 , each of the three key factors are in strategic orientation component.

Table1. Significant test and ranking main themes of researches centers success

\begin{tabular}{|c|c|c|c|c|c|}
\hline Rank & Main themes or component & Mean rank & $X^{2}$ & df & Sig. \\
\hline 1 & Strategic orientation & 7.79 & \multirow[t]{9}{*}{322.55} & \multirow[t]{9}{*}{8} & \multirow[t]{9}{*}{000.0} \\
\hline 2 & Management & 7.71 & & & \\
\hline 3 & Human capital & 6.44 & & & \\
\hline 4 & Support/Advocacy & 6.17 & & & \\
\hline 5 & Projects & 5.92 & & & \\
\hline 6 & Infrastructures & 3.80 & & & \\
\hline 7 & Communication and collaboration & 3.70 & & & \\
\hline 8 & Paradigm/ Ideological & 1.76 & & & \\
\hline 9 & Innovation & 1.71 & & & \\
\hline
\end{tabular}


Table 2. Significant test and ranking sub- themes of researches centers success

\begin{tabular}{|c|c|c|c|c|c|c|}
\hline Theme & Rank & Sub-theme & $\begin{array}{l}\text { Mean } \\
\text { rank }\end{array}$ & $\mathrm{X}^{2}$ & $\mathrm{df}$ & Sig. \\
\hline \multirow{5}{*}{$\begin{array}{l}\text { Strategic } \\
\text { orientation }\end{array}$} & 1 & Science and technology roadmap & 3.32 & \multirow[t]{5}{*}{15.03} & \multirow[t]{5}{*}{4} & \multirow[t]{5}{*}{0.005} \\
\hline & 2 & Strategic plan & 3.22 & & & \\
\hline & 3 & Evaluation indexes & 3.07 & & & \\
\hline & 4 & Research policy (the state and university level) & 2.95 & & & \\
\hline & 5 & Research needs assessment & 2.43 & & & \\
\hline \multirow[t]{6}{*}{ Management } & 1 & Scientific evaluation of centers and members & 4.43 & \multirow[t]{6}{*}{61.49} & \multirow[t]{6}{*}{5} & \multirow[t]{6}{*}{0.000} \\
\hline & 2 & Management and development of research human capital & 4.00 & & & \\
\hline & 3 & Compensation and rewarding system & 3.76 & & & \\
\hline & 4 & Research ethics and intellectual property rights & 3.69 & & & \\
\hline & 5 & Implementation of laws, regulations and guidelines & 2.96 & & & \\
\hline & 6 & Administrative bureaucracy & 2.17 & & & \\
\hline \multirow[t]{5}{*}{ Human capital } & 1 & Committed human resources & 3.69 & \multirow[t]{5}{*}{47.19} & \multirow[t]{5}{*}{4} & \multirow[t]{5}{*}{000.0} \\
\hline & 2 & Capable researchers & 3.45 & & & \\
\hline & 3 & Human resources proportion with the objectives & 3.17 & & & \\
\hline & 4 & Local students and elites & 2.56 & & & \\
\hline & 5 & Foreign professors and students & 2.12 & & & \\
\hline \multirow{5}{*}{$\begin{array}{l}\text { Support / } \\
\text { Advocacy }\end{array}$} & 1 & Financial and budget support & 3.56 & \multirow[t]{5}{*}{12.97} & \multirow[t]{5}{*}{4} & \multirow[t]{5}{*}{0.011} \\
\hline & 2 & Grants & 2.95 & & & \\
\hline & 3 & Officials moral support & 2.91 & & & \\
\hline & 4 & Grants distribution & 2.88 & & & \\
\hline & 5 & Political support & 2.70 & & & \\
\hline \multirow[t]{6}{*}{ Projects } & 1 & Quality of projects & 5.28 & \multirow[t]{6}{*}{40.57} & \multirow[t]{6}{*}{6} & \multirow[t]{6}{*}{0.000} \\
\hline & 2 & Publication of results & 4.47 & & & \\
\hline & 3 & The quantity of projects & 3.95 & & & \\
\hline & 4 & Time for project approval & 3.84 & & & \\
\hline & 5 & Sequential or serial researches & 3.81 & & & \\
\hline & 6 & Special research areas & 3.40 & & & \\
\hline \multirow[t]{4}{*}{ Infrastructures } & 1 & Equipment infrastructure & 2.83 & \multirow[t]{4}{*}{12.59} & \multirow[t]{4}{*}{3} & \multirow[t]{4}{*}{0.006} \\
\hline & 2 & Physical space infrastructure & 2.53 & & & \\
\hline & 3 & Information infrastructure & 2.51 & & & \\
\hline & 4 & Conceptual infrastructure (rules, procedures, values) & 2.13 & & & \\
\hline \multirow{4}{*}{$\begin{array}{l}\text { Communication } \\
\text { and } \\
\text { collaboration }\end{array}$} & 1 & Teamwork & 2.84 & 8.46 & 3 & 0.037 \\
\hline & 2 & International interactive and researches & 2.47 & & & \\
\hline & 3 & Networking & 2.37 & & & \\
\hline & 4 & National collaborative researches & 2.31 & & & \\
\hline Paradigm & 1 & Value based approach to research and researcher & 2.19 & 7.37 & 2 & 0.025 \\
\hline & 2 & Ethics and spirituality & 2.02 & & & \\
\hline & 3 & Officials systematic thinking & 1.79 & & & \\
\hline Innovation & 1 & Innovation in research and implementation & 2.34 & 16.67 & 2 & 0.000 \\
\hline & 2 & The commercialization of research products & 1.97 & & & \\
\hline & 3 & Competitive climate & 1.69 & & & \\
\hline
\end{tabular}

Table 3. Ten key factors of success in research centers

\begin{tabular}{|l|l|l|l|}
\hline Rank & Key factors & Main theme & Mean rank \\
\hline 1 & Science and technology roadmap & Strategic orientation & 29.84 \\
\hline 2 & Strategic plan & Strategic orientation & 29.61 \\
\hline 3 & Evaluation indexes & Strategic orientation & 28.55 \\
\hline 4 & Committed human resources & Human capital & 28.10 \\
\hline 5 & Scientific evaluation of centers and members & Management & 27.18 \\
\hline 6 & Innovation in research and implementation & Innovation & 26.70 \\
\hline 7 & Financial and budget support & Support & 26.69 \\
\hline 8 & Capable researchers & Human capital & 26.61 \\
\hline 9 & Equipment infrastructure & Infrastructures & 26.57 \\
\hline 10 & Teamwork & Communication and Collaboration & 25.50 \\
\hline
\end{tabular}




\section{Discussion}

After the identification and ranking the key factors of success in research centers, strategic orientation, management, human capital, support, projects, infrastructures, communication and collaboration, paradigm and innovation were ranked respectively as the key components of research centers' success. In this ranking, "strategic orientation" was identified as the most important component affecting the success of research centers. Strategic orientation refers to how an organization uses strategy to adapt to and/or change aspects of its environment for a more favorable alignment (14). Today, many researchers have concluded that strategic orientation has a very strong impact on organizational performance and management's expectations (15-17). In this regard, one of the primary requirements for success is having the right strategy and long-term plan. Also, proper planning and strategic development for the future, require appropriate strategic orientation. Davodi and colleagues, in their study, concluded that one of the reasons for the failure of technology development in the knowledge-based companies in Iran was inappropriate strategic orientation (18). This shows that organizations, especially research organizations, should pay serious attention to this issue. These organizations, to achieve their desired position in the competitive environment, need to accurately identify and determine their differentiation strategies. Among the identified factors in this component, three factors included: "science and technology road map", "strategic plan" and "evaluation indexes" and were the most effective factors of success in research centers respectively. Today, using the roadmap and strategic plan has been considered by many managers and planners in different areas. Roadmap is a common way of long-term planning. It's a method of discovering and describing the desired future, and explains the ways to achieve it (19). The results of this study are in accordance with Salami's findings. Salami and colleagues concluded that among 28 critical success factors for science and technology parks in Iran, having a clear strategy and objective were the most important success factors (12). In this study, the "management" component was ranked second in terms of importance. Research centers, due to the nature and type of function, are highly dependent on human resources. So, their major management activities are related to human resources such as conditions of promotion, evaluation, compensation, and so on. In this component, among the factors which have been recognized, respectively three factors of "scientific evaluation of members and centers", "management and development of research human capital" and "compensation and rewarding system" were identified as the most important success factors. Today, due to the interpretability of performance evaluation in both objective and subjective dimensions, using an appropriate tool for performance evaluation is essential (20). That is why the managers and directors of the research centers should focus on scientific methods based on performance, (not just through published articles) and suitable rewarding conditions, to provide the growth and promotion of human capital (21). Somehow, these three factors can be considered as a supplement and complement of each other, because the scientific and correct assessment leads to fair material and spiritual rewards, and continuity of this will lead to the growth of human capital in the centers. In a similar study, Salami and colleagues concluded that managerial factors among the supporting, cultural and social factors were as the most important factors in the success of science and technology parks in Iran (12). Siegel and Westhead also, in their study about the performance of small technology-based firms based in UK technology parks, concluded that management skills were one of the success factors (22). Human capital was identified as the third most important and effective component in the success of research centers. In today's knowledge-based economy, human and intellectual capital is more valuable than physical investment for organizations and businesses. In a sense, this capital is the most strategic for present age organizations, especially for research and knowledge based centers. Therefore organizations, to gain a sustainable competitive advantage, require an identifiable and conscious management for their intellectual capital (21). Results of the study showed that the two important key factors in this component were "committed human resource" and "capable researchers". Undoubtedly, the most important element in the implementation of research centers' tasks, which has great impact in the field of science and economy of each country, are commitment, skill, capability and potential human resources. If research centers have the best of circumstances, equipment and facilities, but don't have committed and capable human capital they will certainly be faced with challenges and problems to achieve their goals and missions. The results of this study are in accordance with Bahari's and Haeri's findings, in which human capital had been detected as the key factor in the success of science and technology parks and research centers in Iran $(6,23)$. According to the results, components of support, projects, infrastructure, communications, paradigm and innovation, respectively, were located in the next rank. The remarkable issue in component ranking is the position of "innovation" that is at the end of the ranking. In the participants' perspective of this, a research centers' innovation theme is less important than other themes in the success of the centers. Although the factor of "innovation in research and implementation" ranked sixth among 42 factors, the two factors of "the commercialization of research products" and "competitive climate" had lower ratings. However, the principle progress of research centers, related to create new ideas, theories, techniques and having the technology-market-based approach and the commercialization of ideas. Of course, the academically and governmental nature of these centers, justified disregarding commercialization and competition between centers and 
researchers. Other key factors identified in this study include: "financial support" in the component of support, "equipment infrastructure" in the component of infrastructures and "group/team work between members and between centers" in the component of communication and collaboration. The results of some studies are in accordance with the findings of this study. Gover's study which was conducted in the UK about success factors of science and technology parks, concluded that communication with universities and research institutions was one of the key success factors (24). Study findings were also in agreement with Harris and colleagues' findings in which they concluded that diversity in organizational, managerial and special skills in science and technology parks require communication between different agencies and institutions for the management and development of parks (25). Also, UK Science Park Association introduced six success factors for scientific parks which include: Accurate control over the activities of the institutions within the park; precision in designing buildings and use of materials (accordance with infrastructures component in this study); professional and efficient management (accordance with the management component in this study); collaboration of universities and research institutions (accordance with communications and collaboration component in the study); access to financial services and support (accordance with financial support factors in this study) and access to growth space (accordance with the innovation factor) (26).

\section{Conclusions}

According to the results, the strategic orientation was the most important component in the success of research centers. Therefore, managers and authorities of research centers should pay more attention to strategic areas in future planning, including the science and technology road map and strategic plan, in order to prevent wasting of the resources, and achieve visions and missions. Besides that, scientific evaluation of members and centers and managing human capital should be put in agenda and appropriate conditions for recruitment and development of committed researchers should be provided. Since the study extracted key success factors of research centers comprehensively, it is suggested that related indicators to each factor are prepared and the research centers of medical universities be evaluated annually using them.

\section{Acknowledgments:}

This project was registered at Health Management Research Centre, Baqiyatallah University of Medical Sciences with contract no 94-238 September 2015. The authors sincerely appreciate all the efforts of individuals who helped us in any way for this study.

\section{Conflict of Interest:}

There is no conflict of interest to be declared.

\section{Authors' contributions:}

ST participated in designing and supervising the study, interpreting data and critical revision of the manuscript. ET participated in gathering data and critical revisions to the manuscript. MH participated in designing the study, gathering data, analyzing, interpreting data and writing the manuscript.

\section{References:}

1) Rastgar A. Structure of research centers in Qom city [MS thesis]. Tehran University; 2000.

2) Evaluation report of research centers. Iran: Ministry of Health; 2001.

3) Lee SS, Osteryoung JS. A comparison of critical success factors for effective operations of university business incubators in the United States and Korea. Journal of small business management. 2004; 42(4): 418-26. doi: 10.1111/j.1540-627X.2004.00120.x.

4) Austin D. Understanding critical success factor analysis. 2002. Available from: https://www.w3.org/2002/ws/arch/2/04/UCSFA.

5) Pellow A, Wilson T. The management information requirements of heads of university departments: a critical success factors approach. Journal of Information Science. 1993; 19(6): 425-37. doi: 10.1177/016555159301900602.

6) Bahari A, Modi B, Yaghubi N, Alamolhodaei H. Identify and prioritize the key success factors of science and technology park in Khorasan Razavi. Roshd-e-Fanavari. 2012; 8(30): 13-21.

7) Freund YP. Critical success factors. Planning Review. 1988; 16(4): 20-3. doi: 10.1108/eb054225.

8) Hanafizade P. Strategic information system. Tehran. 2013.

9) Yaghobi A, Shariati M. The factors affecting the performance of research centers; case study, research centers in former Ministry of Jihad Sazandegi. Iranian Agricultural Extension and Education Journal. 2007; 2(3): $1-12$. 
10) Barragán-Ocaña A, Zubieta-García J. Critical factors toward successful R\&D projects in public research centers: a primer. Journal of Applied Research and Technology. 2013; 11(6): 866-75. doi: 10.1016/S16656423(13)71593-1.

11) Löfsten H, Lindelöf P. Science parks in Sweden-industrial renewal and development? R\&D Management. 2001; 31(3): 309-22. doi: 10.1111/1467-9310.00219.

12) Salami R, Behgozin A, Shafeie M. Identify and assess the critical success factors of science and technology parks in Iran: expert opinion. Roshd-e-Fanavari. 2011; 8(29): 63-72.

13) Hsieh HF, Shannon SE. Three approaches to qualitative content analysis. Qualitative Health Research. 2005; 15(9): 1277-88. doi: 10.1177/1049732305276687.

14) Manu FA, Sriram V. Innovation, marketing strategy, environment, and performance. Journal of business Research. 1996; 35(1): 79-91. doi: 10.1016/0148-2963(95)00056-9.

15) Azhar SM. Strategic orientation and performance: The case of equifinality from a developing market perspective. The Business Review. Cambridge. 2008; 10(2): 120-8.

16) Jantunen A, Nummela N, Puumalainen K, Saarenketo S. Strategic orientations of born globals-Do they really matter? Journal of World Business. 2008; 43(2): 158-70. doi: 10.1016/j.jwb.2007.11.015.

17) Aragón - Sánchez A, Sánchez - Marín G. Strategic orientation, management characteristics, and performance: A study of Spanish SMEs. Journal of Small Business Management. 2005; 43(3): 287-308. doi: 10.1111/j.1540-627X.2005.00138.x.

18) Davodi H, Fomi HS, kalantari K. Investigate the barriers of agricultural technology development in Tehran University of science and technology parks. Journal of Science \& Technology Policy. 2011; 4(4): 1-10.

19) Peymankhah S, Ghafarzadeh M. Comparison of conventional approaches in designing road map of technology strategies. Fifth International Conference on Management: Iran, Tehran; 2007.

20) Andrews R, Boyne GA, Walker RM. Subjective and objective measures of organizational performance: An empirical exploration. Cambridge University Press: 2006; 14-34.

21) Sarcheshme BS, Nokarani B, Madah M. Approach to management of intellectual capital in organizations and research centers: case study Jahad Daneshgahi research centers. Seventh International Conference of Industries and Mines R \& D centers. Iran, Tehran; 2008.

22) Siegel DS, Westhead P, Wright M. Science parks and the performance of new technology-based firms: a review of recent UK evidence and an agenda for future research. Small Business Economics. 2003; 20(2): 177-84. doi: 10.1023/A:1022268100133.

23) Haeri O. Research and development units, national research chain rings. Third Conference of Research and Development Centers of Industries and Mines. Iran, Tehran; 2001.

24) Gower S, Harris F. The funding of, and investment in, British science parks: A review. Journal of Property Finance. 1994; 5(3): 7-18. doi: 10.1108/09588689410078557.

25) Gower SM, Harris FC. Science parks in the UK: regional regenerators or just another form of property development? Property Management. 1994; 12(4): 24-33. doi: 10.1108/02637479410071036.

26) Vilà PC, Pagès JL. Science and technology parks: creating new environments favourable to innovation. Paradigmes. 2008. 